\title{
PENGARUH KINERJA KETARUNAAN TERHADAP TINGKAT RESELIANCE TARUNA DI GEDUNG PEMBINAAN KARAKTER POLITEKNIK BUMI AKPELNI
}

\author{
B.L Hentri Widodo ${ }^{1 *}$, Tini Utami ${ }^{1}$, Eviana Diah Kusumawati ${ }^{1}$ \\ Program Studi Nautika, Politeknik Bumi Akpelni \\ Jl. Pawiyatan Luhur II/17, Bendan Dhuwur, Semarang. \\ "Email: bl.hentri@akpelni.ac.id
}

\begin{abstract}
Abstrak
Penelitian ini bertujuan untuk melihat kondisi nyata tingkat kinerja ketarunaan dan kemampuan reseliance di gedung pembinaan karakter Politeknik Bumi Akpelni, serta mendiskripsikan tentang pengaruh kinerja ketarunaan terhadap tingkat reseliance.Penelitian ini diharapkan nantinya memberikan masukan dan atau solusi serta penerapan praktis dalam mengatasi kinerja ketarunaan agar menjadikan lebih baik lagi juga peningkatan kemampuan reseliance taruna di gedung pembentukan dan pembinaan karakter Politeknik Bumi Akpelni. Populasi dalam penelitian ini adalah taruna/taruni angkatan 56 dengan jumlah 370 orang yang melaksanakan pembentukan dan pembinaan karakter di gedung Pembinaan dan Pembentukan Karakter Politeknik Bumi Akpelni.Pengumpulan data dengan metode kuisioner.Uji intrumen ini dilakukan terhadap 79 tarunal taruni angkatan 56 prodiNautika, Teknika dan KPN. Analisi data yang digunakan adalah teknik analisis regresi. Hasil penelitian ini adalah (1) Berdasarkan uji hipotesis parsial/ uji T diperoleh hasil bahwa kinerja ketarunaan berpengaruh positif signifikan terhadap tingkat reseliance (2) Sumbangan efektif kinerja ketarunaan terhadap reseliance taruna sebesar 13,9 persen.
\end{abstract}

Kata kunci: Kinerja ketarunaan, tingkat reseliance, Pembinaan karakter

\section{PENDAHULUAN}

Ketahanan atau resilience seorang individu dalam mengatasi permasalahan kehidupan akan tampak pada saat individu menghadapi berbagai masalah. Seseorang individu bisa memilki kerentaan menghadapi masalah yang sebenarnya merupakan masalah sederhana bagi individu yang lain. Seperti waktu sekarang diera teknologi dan globalisasi sangat membutuhkan sumber daya manusia yang berkwalitas. Tuntutan ini sangat mendesak di era teknologi dan globaliasasi yang membawa dampak yang signifikan bagi kehidupan sehari-hari dan tentunya harus disikapi dengan bijaksana. Taruna pemula Politeknik Bumi Akpelni sebagai salah satu calon sumberdaya manusia yang harus memiliki ketangguhan dan kemampuan bersaing untuk dapat menjadi insan yang memiliki kompetensi yang berkualitas, Jika tidak dipersiapkan dengan baik maka akan menjadi orang yang tersingkir. Taruna Pemula adalah taruna/i yang duduk pada tingkat -1 yaitu semester satu di Politeknik
Bumi Akpelni, dan Taruna adalah sebutan bagi mahasiswa/mahasiswi Politeknik Bumi Akpelni sebagai peserta didik yang ditetapkan dengan Keputusan Direktur. Sedangkan Ketarunan adalah organisasi yang dibentuk untuk melatih, memupuk dan mengembangkan jiwa kepemimpinan,minat bakat dan potensi dari taruna/taruni Politeknik Bumi Akpelni.( psl.16, Tatip Poltekpelni.).

Dalam undang-undang sistem

Pendidikan Nasional (UU Sisdiknas no.20 tahun 2003) dijelaskan bahwa Pendidikan Nasional mengembangkan kemampuan dan membentuk watak serta peradapan bangsa yang bermatabat dalam rangka mencerdaskan kehidupan bangsa dan bertujuan untuk bekembangnya prestasi peserta didik agar menjadi manusia yang beriman dan bertakwa kepada Tuhan Yang Maha Esa, berakhlak, sehat, berilmu, cakap, kreatif, mandiri dan menjadi warga negara yang demokratis serta bertanggungjawab.

Politeknik Bumi Akpelni merupakan salah satu pendidikan yang menyelenggarakan 
program pendidikan berasrama (Boarding School) dimana di Politeknik Bumi Akpelni disebut sebagai Gedung Pembentukan dan Pembinaan Karakter atau yang dikenal dengan Arsrama adalah gedung tempat tinggal taruna/taruni Politeknik Bumi Akpelni dalam menjalani pembinaan dan pembentukan karakter selama masa pendidikan dan pelatihan di lingkungan Politeknik Bumi Akpelni sejak semester satu sampai dengan semester empat.

Diharapkan didalam Gedung Pembentukan dan Pembinaan Karakter ini Taruna dapat mengembangkan tentang cara bersosialisasi dengan sesama teman, dapat menumbuhkan rasa kekeluargaan dan meningkatkan jiwa Leandership atau kepemimpinan. Disamping itu diharapkan juga akan dapat memberikan pembelajaran tentang sopan santun, etika, bertuturkata dan menyampaikan pendapat, hingga bermusyawarah untuk mufakat yang diterapkan dalam kehidupan berorganisasi nantinya. Sebagai salah satu bentuk untuk mencapai tujuan dari Institusi agar lulusan dapat memiliki jiwa yang beraklak mulia,mandiri, berkarakter, dan inovatif disegala bidang maka diwajibkan bagi taruna aktif yang sedang melaksanakan pendidikan untuk tinggal di Gedung Pembentukan dan Pembinaan Karakter selama 2 tahun mulai dari taruna tersebut lulus seleksi Penerimaan Taruna Baru dan telah melakukan Regristasi atau daftar ulang (Semester I ) sesuai ketentuan yang berlaku sampai dengan semester IV tahun berjalan.

Di Gedung Pembentukan dan Pembinaan Karakter, dituntut setiap hari Taruna harus mampu melakukan kegiatankegiatannya secara mandiri, tidak lagi tergantung pada orang tua seperti pada waktu tinggal dirumah. Kemandirian menunjukan pada adanya suatu kepercayaan akan kemampuan diri sendiri untuk dapat menyesuaikan persoalan-persoalan yang timbul tanpa bantuan orang lain, tanpa dikontrol oleh orang lain, dapat melakukan kegiatan dan menyelesaikan sendiri masalah-masalah yang dihadapinya, hal tersebut sering menimbulkan sumber stress yang dimiliki Taruna. Permasalahan dan tantangan serta kesulitan pada Taruna merupakan suatu fenomena hidup yang tidak bisa dihindari.Untuk dapat mengatasi berbagai tantangan, permasalahan yang menimbulkan stress, depresi dan kecemasan maka setiap taruna harus bisa menjadi resilliensi yaitu dapat bangkit, mampu untuk bertahan, dan memperbaiki kekecewaan yang dihadapinya.

Didalam Gedung Pembentukan dan Pembinaan Karakter tersebut Taruna Pemula akan diawasi dan dibina oleh Pembina taruna, Perwira Resimen, Instruktur Ketarunaan serta diwadahi organisasi " Resimen Korps Taruna " adalah wadah pembinaan kemampuan beroganisasi dan kepemimpinan, penyaluran minat dan bakat serta sebagai sarana untuk melaksanakan semua kegiatan Ketarunaan di lingkungan Politeknik Bumi Akpelni.

Katahanan atau Resilence seorang individu dalam mengatasi suatu permasalahan hidup tampak pada saat individu menghadapi berbagai masalah. Seseorang individu bisa memiliki kerentanan terhadap masalah yang sebenarnya atau yang terjadi bisa merupakan masalah sederhana bagi individu lain. Bagi Taruna yang memiliki pribadi resilience yang tinggi akan dibutuhkan untuk dapat mengatasi berbagai permasalahan dalam kehidupan dan menunjukkan prestasi dalam kinerjanya. Ketarunaan memberikan suatu kegiatan yang bersifat tetap atau disebut PHST (Perintah Harian Sifat Tetap) dimana taruna /taruni harus melaksanakan kegiatan yang dimulai dari bangun pagi, pelaksanaan sholat berjamaah di masjid untuk mewujudkan manusia yang bertaqwa kepada Tuhan Yang Maha Esa. Setelah itu jajaran resimen sudah mempersiapkan kegiatan berikutnya yaitu olahraraga pagi dan apel pagi, guna membentuk manusia yang disiplin, baik disiplin waktu maupun disiplin terhadap tanggung jawabnya 
sebagai taruna/taruni yang sedang menempuh pembelajaran didalam suatu lembaga pendidikan. Selain itu setiap hari sabtu diadakan kegiatan yang sifatnya untuk kebersamaan yaitu binafital dimana pada proses ini jajaran resimen memberikan porsi pelatihan terhadap fisik taruna/ taruni agar tetap tangguh dan sehat baik jasmani maupun rohani.Pentingnya seorang Taruna sebagai individu yang tangguh memiliki kemampuan resilience tinggi akan menjadi pribadi yang tangguh,dapat menjadi panutan dan memiliki ketahanan dalam menghadapi permasalahan dalam kehidupan, juga dalam lapangan pekerjaan nantinya.

Jadi pada dasarnya pendidikan karakter itu bertujuan untuk membentuk pribadi yang tangguh, bermoral, berklak mulia, berjiwa gotong royong, berkepribadian mandiri berjiwa patriotik dan berorientasi pada ilmu pengetahuan yang didasari dari nilai nbilai keimanan dan ketaqwaan terhadap Tuhan Yang Maha Esa.

Permasalahan yang terjadi pada Taruna yang tinggal di Gedung Pembentukan dan Pembinaan Karakter lebih beragam karena harus mengalami rutinitas kehidupan didalam asrama,tuntutan Akademis,lingkungan, dan sosial budaya, serta tekanan yang berbeda dibandingkan dengan mahasiswa pada umumnya. Permasalahan yang terjadi terhadap taruna tersebut dapat menjadi stressor bagi diri mereka. Dari hasil penelitian yang dilakukan Hayati (Ageng Susena 2013), menunjukkan bahwa jika individu merasa stress dan tidak nyaman dengan keadaan yang ada, maka dirinya akan menunjukkan sikap bermusuhan.

\section{LANDASAN TEORI Resillience}

Resilliensi adalah kemampuan untuk mengatasi dan beradaptasi terhadap kejadian yang berat atau masalah yang terjadi dalam kehidupan. Bertahan dalam keadaan tertekan dan bahkan berhadapan dengan kesengsaraan (adversity) atau trauma yang dialami dalam kehidupannya (Reivich \& Shatte, 2002).

Jadi Reselliensi yang dimaksud disini adalah kemampuan taruna/ taruni adalah kemampuan taruna/taruni angkatan 56 terutama pada saat memasuki proses pembentukan jadi diri didalam gedung pembentukan karakter dengan segala kegiatan yang bersifat kebersamaan, gotong royong dan berkepribadian mandiri untuk mempersiapkan nantinya pada saat didunia kerja nanti.

\section{Pembinaan Karakter}

Karakter (Tadkiroatul Musfiroh UNY 2008) adalah karakter mengacu pada serangkain sikap atau kepribadian manusia, prilaku,motivasi, dan keterampilan.

Pembinaan atau pendidikan karakter adalah penanaman jiwa atau kepribadian setiap manusia atau disini adalah taruna yang meliputi penanaman dalam hal ilmu pengetahuan, penanaman kesadaran dan kepedulian taruna terhadap lingkungan dan sesama manusia, untuk melaksanakan suatu tindakan pada nilai nilai kebaikan yang ada.

\section{Kinerja}

1. Difinisi Kinerja

Menurut Sutrisno (2016), pengertian kinerja adalah sebagian hasil yang telah dicapai seseorang dari tingkah kerjanya dalam melaksanakan aktivitas

Sehingga dapat disimpulkan pengertian kinerja adalah sebagai pelaksanaan tugas dalam ukuran dan waktu yang ditentukan, sesuai dengan tanggungjawab yang diberikan yang membutuhkan pemahaman dan pengetahuan, keahlian, kepiawaian dan perilaku yang dipelukan dalam melaksanakan pekerjaa sesuai kriteria yang berlaku.

2. Indikator Kinerja

Performance atau kinerja merupakan hasil atau keluaran dari suatu proses Nurlaila (2010), Sedangkan menurut 
Dessler (2000), Kinerja merupakan prestasi kerja, yaitu perbandingan antara hasil kerja dengan standar yang ditetapkan. Demikian juga yang dimaksud dengan Kinerja adalah hasil kerja baik secara kualitas maupun kuantitas yang dicapai oleh seseorang dalam melaksanakan tugas sesuai tanggung jawab yang diberikan (Mangkunagara, 2002). Indikator untuk mengukur kinerja secara individu ada enam indikator, yaitu (Robbins, 2006):

1. Kualitas.

2. Kuantitas.

3. Ketepatan waktu

4. Efektivitas.

5. Kemandirian.

6. Komitmen kerja.

Berdasarkan pendapat diatas disimpukan bahwa indikator kinerja adalah merupakan pengetahuan, suatu keahlian, persepsi, prestasi kerja, kualitas maupun kuantitas, pengaturan kerja dan proses.

3. Faktor-faktor yang Mempengaruhi Kinerja

1) Efektifitas dan efisiensi

2) Otoritas (wewenang)

3) Disiplin

4) Inisiatif

4. Karakteristik Kinerja

Karakteristik orang yang mempunyai kinerja tinggi adalah sebagai berikut (Mangkunegara, 2002):

1. Memiliki tanggung jawab pribadi yang tinggi.

2. Berani mengambil dan menanggung resiko yang dihadapi.

3. Memiliki tujuan yang realistis.

4. Memiliki rencana kerja yang menyeluruh dan berjuang untuk merealisasi tujuannya.

5. Memanfaatkan umpan balik (feed back) yang konkrit dalam seluruh kegiatan kerja yang dilakukannya.

6. Mencari kesempatan untuk merealisasikan rencana yang telah diprogramkan

\section{METODE \\ Jenis Penelitian}

Metodologi yang digunakan dalam penelitian ini adalah metode kuantitatif dengan mengkaji hubungan antara kinerja ketarunaan terhadap tingkat resiliance taruna di gedung pembinaan karakter Politeknik Bumi Akpelni Semarang. Uji statistik yang digunakan adalah analisis regresi komponen utama dengan pertimbangan untuk mengatasi terjadinya multikolinearitas tinggi antara variablevariabel bebas.

\section{Subyek penelitian}

Populasi target dalam penelitian ini adalah taruna/taruni Politeknik Bumi Akpelni Semarang, sedangkan populasi terjangkau (populasi yang dapat dijangkau oleh peneliti) adalah taruna Politeknik Bumi Akpelni Semarang angkatan 56 prodi KPN, Nautika dan Teknika sebanyak 79 responden dari jumlah total populasi target 370 taruna.

\section{Teknik pengumpulan data.}

Teknik pengambilan sampel menggunakan teknik sampel acak terstratifikasi (stratified random sampling), yakni mengambil sampel secara acak proporsional dari taruna prodi KPN, Nautika dan Teknika Politeknik Bumi Akpelni Semarang dengan menggunakan kuisioner. Variabel yang digunakan adalah kinerja ketarunaan (instrumen yang dgunakan pengetahuan, keahlian, persepsi, kondisi lingkungan kerja, kepemimpinan, penghargaan) dan untuk tingkat resiliance taruna (instrumen yang dgunakan emotion regulation, impuls control, optimism, causal, analysis, empathy, self-efficacy, reaching).

$$
\text { Penentuan jumlah sampel }
$$

menggunakan rumusan Bungin (2009), sebagai berikut:

$$
n=\frac{N}{N \cdot d^{2}+1}
$$

$$
\begin{aligned}
& \mathrm{n}=\text { Ukuran sampel } \\
& \mathrm{N}=\text { Ukuran populasi }
\end{aligned}
$$


$\mathrm{d}=$ Nilai presisi (ditentukan, yaitu $90 \%$ atau $\mathrm{a}=0,01$ )

\section{Analisis Data}

Analisis data yang digunakan adalah analisis regresi.

\section{a. Model Analisis}

$$
\hat{Y}=a+b X
$$

Dimana :

$\mathrm{Y}=$ tingkat resiliance taruna

$\mathrm{X}=$ kinerja ketarunaan

$\mathrm{b}=$ koefisien regresi

$\mathrm{a}=$ residual, yaitu selisih nilai respon yang sesungguhnya dengan nilai taksiran yang diperoleh dari model.

\section{b. Tahap Analisis}

1. Validitas dan reliabilitas Alat Ukur Validitas yang digunakan dalam penelitian ini adalah validitas konstruk, yaitu prosedur pengujuan validitas yang berangkat dari hasil komputasi interkorelasi diantara berbagai hasil test yang kemudian diikuti oleh analisis lebih lanjut terhadap matriks korelasi yang diperoleh ( Azwar S, 2008 ).

Sedangkan reliabilitas dalam penelitian ini diuji menggunakan cara konsistensi internal, dengan teknik Cronbach Alpha.Koefisien ini bervariai dari 0 sapai 1 (Azwar S, 2008).

2. Analisa Data

Analisa data untuk menguji hipotesis dalam penelitian ini menggunakan rumus korelasi analisis regresi untuk mengukur variable $\mathrm{X}$ dan variable dependen (Y)

\section{HASIL DAN PEMBAHASAN \\ Validitas dan Realibilitas Alat Ukur}

Validitas menunjukan sejauh mana alat ukur tersebut memenuhi fungsinya, dmana validitas alat ukur tersebut menunjukan sejauh mana alat ukur itu mengukur apa yang seharusnya diukur oleh alat ukur tersebut.

Pengujian validitas dalam penelitian ini menggunakan bantuan program SPSS 25.00. Syarat minimum untuk dianggap memenuhi syarat bahwa item kuesioner penelitian valid adalah kalau $\mathrm{r}>\mathrm{r}$ tabel, sehingga item soal dianggap valid jika memiliki nilai $r$ lebih besar dari $r$ tabel.

Pada penelitian ini dilakukan uji validitas kepada 79 sampel penelitian, sehingga item soal dikatakan valid jika nilai $r$ hitungnya lebih besar dari 0.227 dengan signifikansi $<0.05$, Sedangkan uji reliabilitas menunjuk pada suatu pengertian bahwa sesuatu instrumen cukup dapat dipercaya untuk digunakan sebagai alat pengumpul data karena instrumen tersebut sudah baik (Arikunto, 2006:154).

\section{Validitas dan Reliabilitas Kinerja Ketarunaan (X)}

Uji validitas menggunakan pearson product moment pada 24 item soal yang diujikan, diperoleh hasil bahwa seluruh item soal memiliki nilai $r>0.227$ maka dapat diambil kesimpulan seluruh item soal valid. Sedangkan uji reliabilitas didapatkan nilai cronbach alpha sebesar $0.308<0.6$ maka alat ukur dapat dikatakan kurang reliabel dan termasuk dalam kategori reliabilitas rendah.

Tabel 1. Reliability Statistics

\begin{tabular}{|c|c|}
\hline $\begin{array}{c}\text { Cronbach's } \\
\text { Alpha }\end{array}$ & N of Items \\
\hline .308 & 24 \\
\hline
\end{tabular}

Sumber : Data Primer 2021

\section{Validitas dan Reliabilitas Resiliance Taruna (Y)}

Uji validitas menggunakan pearson product moment pada 28 item soal yang diujikan, diperoleh hasil bahwa seluruh item soal memiliki nilai $r>0.227$ maka dapat diambil kesimpulan seluruh item soal valid. Sedangkan uji reliabilitas didapatkan nilai cronbach alpha sebesar $0.658>0.6$ maka alat ukur dapat dikatakan reliabel dan termasuk dalam kategori reliabilitas tinggi.

Tabel 2. Reliability Statistics 


\begin{tabular}{|c|c|}
\hline $\begin{array}{c}\text { Cronbach's } \\
\text { Alpha }\end{array}$ & N of Items \\
\hline .658 & 28 \\
\hline
\end{tabular}

Sumber : Data Primer 2021

\section{Analisis Regresi}

Analisis regresi ini untuk mengetahui arah hubungan antara variabel independen dengan variabel dependen apakah masing-masing variabel independen berhubungan positif atau negatif dan untuk memprediksi nilai dari variabel dependen apabila nilai variabel independen mengalami kenaikan atau penurunan.

\section{Koefisien Determinasi}

Uji determinasi diigunakan untuk mengetahui persentase sumbangan pengaruh Variabel independen terhadap variabel dependent.

Koefisien determinasi pada intinya mengukur seberapa jauh kemampuan model dalam menerangkan variasi dari variabel dependen.

Koefisien determinasi dapat diperoleh dengan cara mengkuadratkan koefisien korelasi atau $R$ Squared $\left(\mathrm{R}^{2}\right)$. Hasil uji determinasi dapat dilihat pada tabel berikut

Tabel 3. Model Summary

\begin{tabular}{|c|c|c|c|c|}
\hline Model & $\mathrm{R}$ & $\begin{array}{c}\mathrm{R} \\
\text { Square }\end{array}$ & $\begin{array}{c}\text { Adjuste } \\
\mathrm{d} \mathrm{R} \\
\text { Square }\end{array}$ & $\begin{array}{c}\text { Std. Error } \\
\text { of the } \\
\text { Estimate }\end{array}$ \\
\hline 1 & $\begin{array}{c}.37 \\
3^{\mathrm{a}}\end{array}$ & .139 & .128 & 5.692 \\
\hline & & & & \\
\hline
\end{tabular}

Sumber : Data Primer 2021

a. Predictors: (Constant), KINERJA KETARUNAAN (X)

Berdasarkan output diatas didapatkan nilai $\mathrm{R}^{2}$ sebesar 0.139 , sehingga dapat diambil kesimpulan bahwa Kinerja Ketarunaan mempengaruhi Resiliance Taruna sebesar $13.9 \%$. Sedangkan $86.1 \%$ Kinerja Ketarunaan dipengaruhi oleh variabel-variabel lainnya yang tidak diteliti dalam penelitian ini.

\section{Uji T}

Analisis pengujian individual atau parsial (Uji t) diperlukan untuk mengetahui bahwa variabel independen secara parsial mempunyai pengaruh yang signifikan terhadap variabel dependen. Pengambilan keputusan dalam uji ini didasarkan pada tingkat signifikansi sebesar $1 \%$ atau 0,01 . Hasil uji T dapat dilihat pada tabel berikut;

Tabel 4. Coefficients ${ }^{\mathrm{a}}$

\begin{tabular}{|c|c|c|c|c|c|c|}
\hline \multirow{2}{*}{\multicolumn{2}{|c|}{ Model }} & \multicolumn{2}{|c|}{$\begin{array}{l}\text { Unstandardize } \\
\text { d Coefficients }\end{array}$} & $\begin{array}{l}\text { Standar } \\
\text { dized }\end{array}$ & \multirow[t]{2}{*}{$\mathrm{t}$} & \multirow[t]{2}{*}{$\begin{array}{l}\mathrm{Si} \\
\mathrm{g} .\end{array}$} \\
\hline & & B & $\begin{array}{c}\text { Std } \\
\text { Err } \\
\text { or }\end{array}$ & Beta & & \\
\hline & $\begin{array}{l}\text { (Con } \\
\text { stan } \\
\text { t) }\end{array}$ & 47.924 & $\begin{array}{r}8.0 \\
68\end{array}$ & & $\begin{array}{r}5.9 \\
40\end{array}$ & \\
\hline 1 & \begin{tabular}{|l} 
KINE \\
RJA \\
KET \\
ARU \\
NAA \\
N \\
$(X)$
\end{tabular} & .417 & $\begin{array}{r}.11 \\
8\end{array}$ & .373 & $\begin{array}{r}3.5 \\
23\end{array}$ & \\
\hline
\end{tabular}

Sumber : Data Primer 2021

I-ODependent Variable: RESILIENCE (Y)

Kesimpulan uji T:

Kinerja Ketarunaan memperoleh nilai t hitung sebesar dan nilai 3.523 $>1.995$ signifikansi sebesar $0.001<0.01$, sehingga dapat diambil kesimpulan bahwa Kinerja Ketarunaan berpengaruh positif signifikan terhadap Resiliance Taruna.

\section{Analisis Persamaan Regresi Linear}

Berdasarkan output uji T diatas, dapat dirumuskan persamaan regresi linear 
sederhana pada penelitian ini sebagai berikut:

$$
\mathrm{Y}=47.924+0.417 \mathrm{X}
$$

a. Nilai konstanta diperoleh nilai sebesar 47.924 artinya jika tidak ada Kinerja Ketarunaan maka nilai konstan dari Resiliance Taruna adalah sebesar 47.924.

b. Angka koefisien regresi dari Kinerja Ketarunaan adalah sebesar 0.417 , artinya setiap penambahan $1 \%$ dari Kinerja Ketarunaan maka nilai dari Resiliance Taruna akan meningkat sebesar 0.417 .

\section{Uji F}

Uji $F$ dikenal dengan Uji serentak untuk melihat bagaimanakah pengaruh semua variabel bebasnya secara bersamasama terhadap variabel terikatnya.

Uji simultan (uji F) bertujuan untuk menunjukkan apakah semua variabel independen (bebas) mempengaruhi variabel dependen (terikat) secara bersama-sama atau simultan. Uji ini dapat dilakukan melalui pengamatan nilai signifikansi pada tingkat yang digunakan.

Dalam penelitian ini tingkat a yang digunakan adalah sebesar 5\%, dimana variabel $\mathrm{X}$ dikatakan berpengaruh simultan terhadap variabel $\mathrm{Y}$ jika nilai signifikansinya $<0.01$. Hasil uji $\mathrm{F}$ dapat dilihat pada tabel anova berikut

Tabel 5. ANOVA ${ }^{\mathrm{a}}$

\begin{tabular}{|c|c|c|c|c|c|}
\hline Model & $\begin{array}{c}\text { Sum } \\
\text { of } \\
\text { Squar } \\
\text { es }\end{array}$ & df & $\begin{array}{c}\text { Mean } \\
\text { Square }\end{array}$ & F & Sig. \\
\hline Regres & $\begin{array}{c}402.0 \\
\text { sion }\end{array}$ & 2 & 402.03 & 12.4 & .001 \\
Residu & 2494. & 77 & 32.401 & 08 & b \\
al & 900 & & & & \\
Total & $\begin{array}{c}2896 . \\
937\end{array}$ & 79 & & & \\
\hline
\end{tabular}

Sumber : Data Primer 2021

a. Dependent Variable:RESILIENCE (Y)

\section{b. Predictors: (Constant), KINERJA KETARUNAAN (X)}

Berdasarkan output diatas diperoleh nilai signifikansi sebesar $0.001<0.01$, maka dapat disimpulkan bahwa Kinerja Ketarunaan berpengaruh secara simultan/memiliki pengaruh secara bersama-sama terhadap Resiliance Taruna.

\section{KESIMPULAN}

Dari hasil penelitian didapatkan bahwa terdapat hubungan dan pengaruh positif yang dilakukan oleh unit ketarunaan kepada angkatan 56 sebanyak 370 dan juga signifikan antara kinerja ketarunaan terhadap resiliance taruna artinya semakin tinggi kinerja ketarunaan maka semakin tinggi pula resiliance taruna. Hubungan kinerja ketarunaan jika terjadi penambahan terhadap tingkat kinerja 1 persen akan berdampak peningkatan ketahanan terhadap taruna sebesar 0,417.

Sumbangan efektif kinerja ketarunaan yang dilakukan oleh unit ketarunaan terhadap resiliance taruna sebesar $13.9 \%$ sehingga masih terdapat $86.1 \%$ faktor-faktor lain yang berpengaruh terhadap ketahanan terhadap taruna dan taruni angkatan 56 selama berada di dalam gedung pembinaan karakter.

\section{DAFTAR PUSTAKA}

Arikunto, Suharsimi. 2002. Prosedur Penelitian - Suatu Pendekatan Praktek, Cetakan Kedua Belas (Edisi Revisi V). Jakarta: PT. Rineka Cipta.

Azwar, S. 2008. Sikap manusia: Teori dan pengukurannya (ed.4). Yogyakarta: Pustaka Pelajar.

Mangkunegara, Anwar Prabu . 2002. Manajemen Sumber Daya Manusia. Remaja Rosdakarya. Bandung

Nurlaila, 2010. Manajemen Sumber Daya Manusia I. Penerbit LepKhair.

Reivich dan Shatte, 2002, Psychosocial Resilience. American Journal of Orthopsychiatry, 57, 316. doi:10.1111/j. 1939-0025.1987.tb03541.x

Robbins, Stephen P., 2006. Perilaku 
Organisasi Jilid II, Alih Bahasa HadayanaPujaatmaka, Jakarta, Prenhalindo.

Surat Keputusan Direktur No.279 /PBA/K.IV/2019 tanggal 29 April 2010 Tentang Peraturan Tata Tertib Taruna Politeknik Bumi Akpelni.

Surat Keputusan Direktur No.280 /PBA/K.IV/2019 tanggal 29 April 2010 Tentang Peraturan Dinas Dalam Taruna Politeknik Bumi Akpelni.

UU No. 20 tahun 2003 tentang Sistem Pendidikan Nasional

Media, Neliti, 2021, Pendidikan Karakter di Perguruan Tinggi Menyikapi dekandensi moral dikalangan, https://media.neliti.com/media/public ations/4995-ID-pendidikan-karakterdi-perguruan-tinggi-menyikapidekandensi-moral-di-kalangan-g.pdf di akses 12 September 2021 